\title{
Subcortical Ischemic Change as a Predictor of Driving Cessation in the Elderly
}

\author{
Mi Jang ${ }^{1}$, Chang Hyung Hong ${ }^{2}$, Hyun-Chung $\mathrm{Kim}^{3}$, Seong Hye $\mathrm{Choi}^{4}$, Sang Won Seo ${ }^{5}$, Seong Yoon Kim \\ Duk L. Na ${ }^{5}$, Yunhwan Lee ${ }^{7}, \mathrm{Ki}$ Jung Chang ${ }^{8}$, Hyun Woong Roh ${ }^{9}$, and Sang Joon Son ${ }^{2}$ \\ 1'Department of General Psychiatry, National Center for Mental Health, Seoul, Republic of Korea \\ ${ }^{2}$ Department of Psychiatry, Ajou University School of Medicine, Suwon, Republic of Korea \\ ${ }^{3}$ Department of Psychiatry, National Medical Center of Korea, Seoul, Republic of Korea \\ ${ }^{4}$ Department of Neurology, Inha University College of Medicine, Incheon, Republic of Korea \\ ${ }^{5}$ Department of Neurology, Samsung Medical Center, Seoul, Republic of Korea \\ ${ }^{6}$ Department of Psychiatry, Asan Medical Center, Seoul, Republic of Korea \\ ${ }^{7}$ Department of Preventive Medicine and Public Health, Ajou University School of Medicine, Suwon, Republic of Korea \\ ${ }^{8}$ Department of Psychiatry, Ajou Good Hospital, Suwon, Republic of Korea \\ ${ }^{9}$ Department of Brain Science, Ajou University School of Medicine, Suwon, Republic of Korea
}

Objective Motor, perceptual, and cognitive functions are known to affect driving competence. Subcortical ischemic changes on brain magnetic resonance imaging (MRI) can reflect reduction in cognitive and motor performance. However, few studies have reported the relationship between subcortical ischemic changes and driving competence of the elderly. Thus, the objective of this study was to investigate the association between subcortical ischemic changes on MRI and driving abilities of the elderly.

Methods Participants $(\mathrm{n}=540)$ were drawn from a nationwide, multicenter, hospital-based, longitudinal cohort. Each participant underwent MRI scan and interview for driving capacity categorized into 'now driving' and 'driving cessation (driven before, not driving now)'. Participants were divided into three groups (mild, $n=389$; moderate, $n=116$; and severe, $n=35$ ) depending on the degree of white matter hyperintensity (WMH) on MRI at baseline. Driving status was evaluated at follow-up. Statistical analyses were conducted using $\chi^{2}$ test, analysis of variance (ANOVA), structured equation model (SEM), and generalized estimating equation (GEE).

Results In SEM, greater baseline degree of WMH was directly associated with driving cessation regardless of cognitive or motor dysfunction $(\beta=-0.110, p<0.001)$. In GEE models after controlling for age, sex, education, cognitive, and motor dysfunction, more severe change in the degree of WMH was associated with faster change from 'now driving' state to 'driving cessation' state over time in the elderly $(\beta=-0.508, \mathrm{p}<0.001)$.

Conclusion In both cross-sectional and longitudinal results, the degree of subcortical ischemic change on MRI might predict driving cessation in the elderly.

Psychiatry Investig 2018;15(12):1162-1167

Key Words Driving, Subcortical ischemic change.

\section{INTRODUCTION}

Driving is the 'ultimate' instrumental activity of daily living $(\mathrm{IADL})^{1}$ as it requires integration of high-level cognitive functions, motor functions, and perception. ${ }^{2,3}$ For the elderly,

\footnotetext{
Received: July 16, 2018 Revised: September 11, 2018

Accepted: October 10, 2018

$\triangle$ Correspondence: Sang Joon Son, MD, PhD

Department of Psychiatry, Ajou University School of Medicine, 164 World cup-ro, Yeongtong-gu, Suwon 16499, Republic of Korea

Tel: +82-31-219-5180, Fax: +82-31-219-5179, E-mail: sjsonpsy@ajou.ac.kr

(ac) This is an Open Access article distributed under the terms of the Creative Commons Attribution Non-Commercial License (http://creativecommons.org/licenses/bync/4.0) which permits unrestricted non-commercial use, distribution, and reproduction in any medium, provided the original work is properly cited.
}

ceasing to drive can interfere with their independent living and decrease their autonomy. ${ }^{4}$ It may also decrease access to social activities, household activities (e.g. shopping), and medical services, thus increasing feelings of isolation and depression. ${ }^{5,6}$ Previous studies have pointed out that ageing itself does not necessarily impair driving or increase the risk of car accidents. ${ }^{7.8}$ However, older people have a high prevalence of cognitive impairment and dementia that may increase the risk of unsafe driving. ${ }^{9}$ Motor dysfunction in Parkinson's disease and Alzheimer's disease can predict driving performance. ${ }^{10,11}$ Since driving abilities of the elderly are linked to safety, it is important to identify factors affecting driving abilities of the elderly population. 
White matter hyperintensity (WMH) is described as area showing increased signal on T2-weighted magnetic resonance image (MRI) including fluid attenuated inversion recovery (FLAIR) image. It generally shows the degree of subcortical ischemic change. ${ }^{12}$ Previous studies have shown that $\mathrm{WMH}$ is associated with cognitive dysfunctions such as global cognitive performance, executive function, processing speed, ${ }^{13}$ and motor dysfunction such as gait dysfunction. ${ }^{14}$ Cognitive and motor dysfunctions combined can negatively affect driving performance in the older population. However, only a few studies have reported the association between the degree of WMH and driving capacities in the elderly.

Therefore, the objective of this study was to investigate the association between WMH and driving cessation in the elderly using a nationwide multicenter hospital-based prospective cohort. Whether the degree of subcortical ischemic changes on MRI could predict the risk of driving cessation in the elderly with or without motor and cognitive dysfunctions was determined in this study.

\section{METHODS}

\section{Participants}

This study was conducted as a part of the Clinical Research for Dementia of South Korea (CREDOS) study, a nationwide multicenter hospital-based prospective cohort study aimed to understand characteristics of Korean patients with dementia. The CREDOS study was conducted from November 2005 to April 2013. It had developed common protocols, including Clinical Evaluation Form and Caregiver Questionnaire Form. It recruited patients with subjective memory impairment, mild cognitive impairment, mild cognitive impairment of subcortical vascular type, and Alzheimer's disease. All patients underwent comprehensive interviews including complete medical history, physical examinations, neurological examinations, neuropsychological assessment, and MRI scans. Brain MRI scans included transaxial T2- and T1-weighted scans and fluid-attenuated inversion recovery (FLAIR) slices. CREDOS neuroimaging visual rating scale was developed by the CREDOS study central committee based on scales of Fazekas ${ }^{15}$ and Scheltens ${ }^{16}$ with modifications. It was described as "Assessment of White Matter Hyperintensities." A more detailed description of the CREDOS study such as inclusion and exclusion criteria is available elsewhere. ${ }^{17}$ The CREDOS study was approved by the Institutional Review Boards of all participating hospitals (AJIRB-MED-SUR-12_027). Written informed consent was obtained from patients and their caregivers after informing them about details of the study. We retrospectively analyzed 540 subjects with data available about driving status at baseline who were followed up at least once after the first visit (mean \pm SD follow-up duration: $2.13 \pm 1.54$ years). Follow-up data of $370 \mathrm{MRI}$ scans were available.

\section{Clinical evaluation and calculation of composite score for motor dysfunction}

Clinical Evaluation Form included the follwoing: 1) history of cognitive decline from the caregiver, 2) Mini-Mental State Examination (MMSE), ${ }^{18} 3$ ) CDR Sum of Boxes score (CDRSOB), ${ }^{19}$ and 4) neurological examination. The Caregiver Questionnaire Form included the following: 1) basic demographic data about the patient and the caregiver, 2) lifestyle including driving status classified as "Now driving", "Not driving", or "Driving cessation (driven before, not driving now)", 3) Barthel activity of daily living (ADL) index, ${ }^{20}$ and 4) Seoul Instrumental $\mathrm{ADL}$ (S-IADL). ${ }^{21}$ In this study, a total of 540 patients with "Now driving" or "Driving cessation (driven before, not driving now)" status at baseline driving evaluation were selected.

All patients underwent neurological examinations, including motor function evaluations such as rigidity, bradykinesia, hemiplegia, ataxia, and Parkinsonian features in relation to gait function. Based on these results, motor dysfunction was scored 0 when there were no abnormalities in any feature. Otherwise, it was scored 1.

\section{Neuropsychological tests and calculation of composite scores for cognition}

All subjects underwent Seoul Neuropsychological Screening Battery (SNSB), a standardized neuropsychological test. ${ }^{22}$ This battery contained tests for attention, language, visuoconstructive function, memory, and frontal/executive function. Scorable tests included Digit Span Backward (DSB), Korean version of Boston Naming Test (K-BNT), ${ }^{23}$ Rey-Osterrieth Complex Figure Test (RCFT), Seoul Verbal Learning Test (SVLT), and Color Word Stroop Test (CWST). Age-, sex-, and education-specific norms for each test based on 447 normal subjects were available. ${ }^{22}$ From these tests, composition score for cognition in relation to driving ability was calculated by summing Z-scores of CWST-color reading, DSB, RCFT-copy, and RCFT-delayed recall reflecting executive function, attention, and visual perception, respectively.

\section{Assessment of WMH}

Three neurologists trained in rating ischemic white matter changes who were blinded to clinical and functional data rated white matter changes on T 2 axial and/or FLAIR images. CREDOS WMH rating scales were developed by the CREDOS study central committee based on Fazekas' scale ${ }^{15}$ with modifications. The longest diameter of white matter changes around lateral ventricles (capping or banding on periventricular areas) or in the white matter (especially the centrum se- 
miovale) was evaluated separately. Periventricular white matter changes were rated as $\mathrm{P} 1(<5 \mathrm{~mm}), \mathrm{P} 2(\geq 5 \mathrm{~mm},<10$ $\mathrm{mm})$, or P3 ( $\geq 10 \mathrm{~mm})$. Deep white matter changes were rated as D1 ( $<10 \mathrm{~mm})$, D2 ( $\geq 10 \mathrm{~mm},<25 \mathrm{~mm})$, or D3 ( $\geq 25$ $\mathrm{mm}$ ). These results were combined to give a final ischemia score of mild, moderate, or severe. Combinations of D1 with P1 (D1P1) and D1 with P2 (D1P2) were classified as 'mild'. Combinations of D2P1, D3P1, D2P2, D3P2, D1P3, and $\mathrm{D} 2 \mathrm{P} 3$ were classified as 'moderate' while combinations of D3 and P3 (D3P3) were classified as 'severe'.

\section{Statistical analyses}

We compared patients with three different degrees of white matter changes on MRI. A $\chi^{2}$ test was performed to examine trends in categorical data. Analysis of variance (ANOVA) was performed for continuous variables to compare groups' scores for demographics and driving status. To evaluate the relative effect of WMH on driving with or without mediation of cognition and motor function, a structured equation model (SEM) was used. We used generalized estimating equation (GEE) to estimate longitudinal effects of WMH on change in driving status. All statistical analyses were performed using SPSS version 22.0 for demographics, AMOS 21.0 for SEM (IBM Corp. Released 2013. IBM SPSS Statistics for Windows, Version 22.0. IBM Corp. Armonk, NY, USA), and GEE package of $\mathrm{R}$ version 3.1.2 for GEE [A language and environment for statistical computing (Version 3.1.2). Vienna, Austria: R Foundation for Statistical Computing].

\section{RESULTS}

\section{Demographics and clinical data according to the degree of WMH}

We analyzed demographic and clinical characteristics according to the degree of WMH. At baseline, 389, 116, and 35 patients were classified as 'mild', 'moderate', and 'severe', respectively. According to the degree of $\mathrm{WMH}$, there were statistically differences in age, sex, driving cessation, and motor dysfunction score. DSB, rey osterrieth complex figure (ROCF)delayed recall, and CWST-color reading on SNSB also showed statistical differences among the three groups (Table 1).

\section{Association of WMH with driving cessation, cognition, and motor dysfunction}

The model (Table 2, Figure 1) depicted both direct and the indirect relationships of WMH with driving cessation, cognition dysfunction, and motor dysfunction. Direct path from $\mathrm{WMH}$ to driving status was statistically significant $(\beta=-0.110$, $\mathrm{p}<0.001)$. WMH was significantly associated with motor dysfunction score $(\beta=0.120, p<0.001)$ and cognition was predictive of driving cessation $(\beta=0.008, \mathrm{p}=0.01)$. However, WMH to cognition $(\beta=-0.295, p=0.486)$ or motor dysfunc-

Table 1. Demographic and clinical characteristics of participants at baseline

\begin{tabular}{|c|c|c|c|c|c|}
\hline & Mild $(\mathrm{N}=389)$ & Moderate $(\mathrm{N}=116)$ & Severe $(\mathrm{N}=35)$ & $\chi^{2}$ or $F$ & $\mathrm{p}$ \\
\hline Gender, male (\%) & $271(69.70)$ & $95(81.90)$ & $30(85.70)$ & 10.28 & 0.008 \\
\hline Age (year) & $66.03 \pm 8.67$ & $70.74 \pm 7.36$ & $73.43 \pm 6.40$ & 22.76 & $<0.001$ \\
\hline Education (year) & $12.29 \pm 4.59$ & $12.22 \pm 4.53$ & $12.86 \pm 5.45$ & 0.01 & 0.764 \\
\hline K-MMSE score & $24.80 \pm 4.49$ & $25.14 \pm 4.09$ & $23.97 \pm 4.17$ & 0.95 & 0.382 \\
\hline CDR-SB score & $2.61 \pm 2.12$ & $2.35 \pm 1.56$ & $3.20 \pm 2.46$ & 2.18 & 0.098 \\
\hline \multicolumn{6}{|l|}{ SNSB } \\
\hline DSB score & $3.52 \pm 1.36$ & $3.16 \pm 1.49$ & $3.09 \pm 1.25$ & 4.48 & 0.015 \\
\hline BNT score & $41.26 \pm 12.48$ & $37.90 \pm 16.55$ & $38.97 \pm 13.01$ & 2.84 & 0.102 \\
\hline ROCF copy score & $28.40 \pm 9.68$ & $27.18 \pm 11.06$ & $26.31 \pm 7.78$ & 1.24 & 0.295 \\
\hline ROCF DR score & $8.79 \pm 7.06$ & $9.00 \pm 7.55$ & $5.29 \pm 5.02$ & 3.46 & 0.001 \\
\hline SVLT DR score & $2.69 \pm 2.88$ & $2.60 \pm 2.91$ & $1.83 \pm 2.36$ & 1.02 & 0.231 \\
\hline CWST CR score & $62.41 \pm 30.59$ & $54.09 \pm 34.18$ & $48.89 \pm 30.83$ & 5.40 & 0.005 \\
\hline B-ADL score & $19.84 \pm 0.98$ & $19.79 \pm 1.11$ & $19.69 \pm 0.87$ & 0.43 & 0.634 \\
\hline Motor dysfunction score & $0.051 \pm 0.22$ & $0.16 \pm 0.36$ & $0.31 \pm 0.47$ & 3.75 & $<0.001$ \\
\hline Driving, now driving (\%) & $292(75.10)$ & $76(65.50)$ & $16(45.70)$ & 14.86 & $<0.001$ \\
\hline
\end{tabular}

Data are presented as mean \pm SD or number (\%). Five hundred and forty participants were tested by SNSB. K-MMSE score: Korean version of Mini Mental State Examination score, CDR-SB: Clinical Dementia Rating Scale-Sum of Boxes, SNSB: Seoul Neuropsychological Screening Battery, DSB: digit span test backward, BNT: Korean version of the Boston Naming Test, ROCF: Rey Osterrieth Complex figure, DR: Delayed Recall, SVLT: Seoul Verbal Learning Test, CWST: Color-Word Stroop test, CR: Color Reading, B-ADL: Barthel Index for the evaluation of basic ADL, Motor dysfunction: Composite Scores for Motor dysfunction, SD: standard deviation 
Table 2. Effects of the predictor (WMH) on driving through mediators (cognition and/or motor dysfunction)

\begin{tabular}{|c|c|c|c|c|c|c|c|c|c|}
\hline & \multicolumn{3}{|c|}{ Cognition } & \multicolumn{3}{|c|}{ Motor dysfunction } & \multicolumn{3}{|c|}{ Driving } \\
\hline & $\beta$ & SE & $\mathrm{p}$ & $\beta$ & SE & $\mathrm{p}$ & $\beta$ & SE & $\mathrm{p}$ \\
\hline WMH & -0.295 & 0.424 & 0.486 & 0.120 & 0.020 & $<0.001$ & -0.110 & 0.033 & $<0.001$ \\
\hline Cognition & & & & & & 0.008 & 0.003 & 0.009 & \\
\hline Motor dysfunction & & & & & & -0.115 & 0.069 & 0.093 & \\
\hline
\end{tabular}

WMH: White Matter Hyperintensities, Cognition: Composite Scores for Cognition, Motor dysfunction: Composite Scores for Motor dysfunction

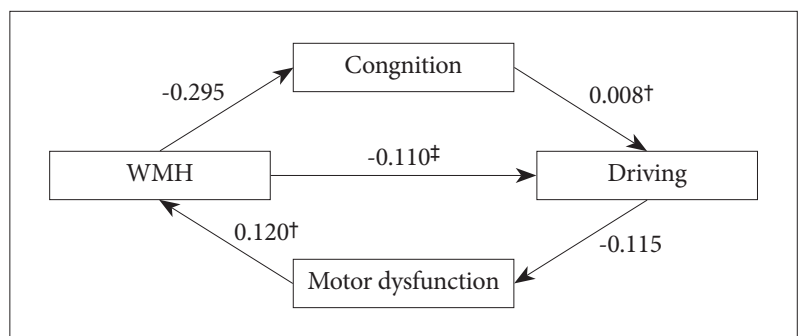

Figure 1. Structure Equation Model. $*<0.05, t<0.01, \neq<0.001$. Values are standardized path coefficients. WMH: White Matter Hyperintensities, Cognition: Composite Scores for Cognition, Motor dysfunction: Composite Scores for Motor dysfunction.

tion score to driving status $(\beta=-0.115, \mathrm{p}=0.093)$ showed no significance. All model fit indices were good $\left(\chi^{2}=12.173\right.$, $\mathrm{df}=1, \mathrm{p}<0.001$, Comparative Fit Index $=0.834$, Goodness of Fit Index=0.989, Adjusted Goodness of Fit Index=0.890, Root Mean Square Residual=0.078).

\section{WMH and progression from "now driving" status to "driving cessation" status}

We examined individual differences in the rate of change from "Now driving" status to "Driving cessation" status using generalized estimating equation models after controlling for age, sex, and education. To examine the relationship between the degree of WMH and the rate of decline in "Now driving" status, we added a baseline and repeatedly measured degrees of $\mathrm{WMH}$ to determine their interaction with time (unadjusted model). In this model, there was a strong association between the rate of change in driving status from "Now driving" to "Driving cessation" and repeatedly measured degrees of WMH from baseline. Age, sex, or education did not affect the association between the degree of $\mathrm{WMH}$ and change in driving status. It remained significant $(\beta=-0.542, \mathrm{p}<0.001)$.

We repeated the model and added terms of several covariates such as composite scores for cognition (Cognition) and composite scores for motor dysfunction (Motor Dysfunction) to determine its effect on the relationship between rate of change in driving status from "Now driving" to "Driving cessation" and repeatedly measured degrees of WMH from baseline. The addition of terms for Cognitive or Motor Dysfunction did not change the association between the degree of WMH and change in driving status. It remained signifi-
Table 3. Regression coefficients in GEE models for driving

\begin{tabular}{lccc}
\hline & Estimate & SE & $\mathrm{p}$ \\
\hline Age & -0.056 & 0.010 & $<0.001$ \\
Sex & 0.311 & 0.170 & 0.067 \\
Education & -0.017 & 0.015 & 0.270 \\
Motor dysfunction & -0.477 & 0.241 & 0.048 \\
Cognition & 0.018 & 0.013 & $<0.001$ \\
WMHt & -0.508 & 0.126 & $<0.001$ \\
\hline
\end{tabular}

Model: Age, Sex, Education, Cognition, Motor dysfunction, and WMHt. Cognition: Composite Scores for Cognition, Motor dysfunction: Composite Scores for Motor dysfunction, WMHt: time-varying White Matter Hyperintensities, GEE: generalized estimating equation

cant $(\beta=-0.508, \mathrm{p}<0.001)$ (Table 3).

\section{DISCUSSION}

This study aimed to examine the association between the degree of WMH and driving cessation in a large cohort study using carefully clinical interviews, neurologic examinations, neuropsychological tests, and MRI scans. Findings of this study showed that the degree of subcortical ischemic changes might be one of predictive factors for driving ability in the elderly with or without mediation of cognitive or motor dysfunction in both cross-sectional and longitudinal aspects.

Due to difficulty in testing driving performance on a road test, the gold standard test for driving competence, ${ }^{24}$ a few studies have explored predictors of driving cessation such as the proxy report of IADLs or cognitive battery. ${ }^{25}$ Cognitive functions, motor functions, and perception are known to be critical for safe driving. ${ }^{2,3}$ In the cognitive domain, previous studies have shown that visual attention, executive function, and visual perception are among the most important factors affecting driving ability. ${ }^{26-33} \mathrm{~A}$ composite score reflecting test performances across multiple cognitive domains is known to be a predictor of driving safety for persons with Alzheimer's disease. ${ }^{10}$ It has been reported that driving performance starts to decline in early disease stage of Alzheimer's disease. ${ }^{10,34}$ Disease progression and severity have been found to be predictors for driving deterioration. ${ }^{34-36}$ In motor functions, the Functional Reach test used for detecting balance impairment has been found to be a probable predictor for 
driving competence. ${ }^{37,38}$ Pegboard test for motor coordination and motor speed and the Get-Up-and-Go task used as part of a global assessment of an individual's fall risk ${ }^{39}$ might also be predictive of driving performance. ${ }^{11}$ Results of the present study are consistent with previous studies about the association of driving ability with cognitive and motor functions in cross-sectional and longitudinal aspects.

Few previous studies have investigated relationships of driving cessation with both cognitive and motor dysfunctions through an integrated approach. The degree of $\mathrm{WMH}$ is known to reflect both cognitive and motor function. WMH reflects disruption of longitudinal tracts located in periventricular and subcortical white matter regions in the brain that link motor function and executive function. It could interfere with bidirectional transfer of information between key motor and cognitive cortical regions. ${ }^{40-42}$ Previous studies have reported that WMH is associated with motor decline such as decreased gait speed and increased gait number. ${ }^{43-48}$ These findings are consistent with results of the present study showing that the degree of WMH can significantly affect motor function which could affect gait function. Meanwhile, WMH could be regarded as a potentially useful intermediate marker to identify cognitive impairment. ${ }^{13}$ Previous studies have suggested that $\mathrm{WMH}$ is associated with global cognitive performance ${ }^{13}$ and specific cognitive deficits such as impaired recall, slowing processing speed, deficient executive planning, ${ }^{49,50}$ and ADL impairment. ${ }^{51-53}$ In our study, there was no significant relationship between WMH and cognition in SEM. Such difference in result might be due to demographic confounding factors and various neurodegenerative factors such as amyloid burden, cerebrovascular disease, and brain atrophy which could not be evaluated in this study. ${ }^{54}$

Interestingly, this study showed that the direct path from WMH to driving status was statistically significant in SEM. In this study, GEE models demonstrated that over time, the more severe the change in the degree of $\mathrm{WMH}$, the more rapid the deterioration in driving performance. This association remained significant after adjusting for age, sex, education, cognition score, and motor dysfunction score known to be crucial for driving competence. Collectively, in both crosssectional and longitudinal aspects, the association between the degree of $\mathrm{WMH}$ and driving is direct and significant. Considering that a surrogate imaging marker has the potential to predict the natural course of the disease with possibility to correlate with relevant clinical features in both cross-sectional and longitudinal studies, ${ }^{55} \mathrm{WMH}$ might be an independent predictive factor for driving cessation in the elderly with or without mediation of cognitive or motor dysfunction.

This study had several limitations. First, other reasons to quit driving such as economic problems were not taken into consideration. Second, the actual decline of driving ability or the risk of an accident could not be determined because driving status was only evaluated by using caregiver questionnaires. Third, MRI finding was classified only by WMH without considering cortical atrophy, lacuna, or others. Fourth, data on driving-sensitive cognitive or motor functions were limited. Further studies are needed to evaluate cognition and motor functions through specific tests focusing more on driving such as actual driving.

Despite these limitations, this study was a well-defined cohort study to report the degree of $\mathrm{WMH}$ and its association with driving cessation. Qualified and systematic tests evaluating cognitive functions and MRI scan were used and results were significant even after adjusting for covariates. In conclusion, subcortical ischemic changes on MRI may be an independent predictive factor for driving cessation. It could indirectly reflect both motor and cognitive functions.

\section{Acknowledgments}

This study was supported by grants from the Korea Health 21 R\&D Project funded by the Ministry of Health \& Welfare, Republic of Korea (HI10C2020 and HI15C0995). The authors want to give special thanks to Dae Ryong Kang and Ja Yeon Kim for their statistical advice.

\section{REFERENCES}

1. Sherman FT. Driving: the ultimate IADL. Geriatrics 2006;61:9-10.

2. De Raedt R, Ponjaert-Kristoffersen I. Predicting at-fault car accidents of older drivers. Accid Anal Prev 2001;33:809-819.

3. Marottoli RA, Cooney LM Jr, Wagner R, Doucette J, Tinetti ME. Predictors of automobile crashes and moving violations among elderly drivers. Ann Intern Med 1994;121:842-846.

4. Hiscock R, Macintyre S, Kearns A, Ellaway A. Means of transport and ontological security: do cars provide psycho-social benefits to their users? Transp Res D Transp Environ 2002;7:119-135.

5. Marottoli RA, Mendes de Leon CF, Glass TA, Williams CS, Cooney LM Jr, Berkman LF, et al. Driving cessation and increased depressive symptoms: prospective evidence from the New Haven EPESE. Established Populations for Epidemiologic Studies of the Elderly. J Am Geriatr Soc 1997;45:202-206.

6. Taylor BD, Tripodes S. The effects of driving cessation on the elderly with dementia and their caregivers. Accid Anal Prev 2001;33:519-528.

7. Wagner JT, Muri RM, Nef T, Mosimann UP. Cognition and driving in older persons. Swiss Med Wkly 2011;140:w13136.

8. Ryan GA, Legge M, Rosman D. Age related changes in drivers' crash risk and crash type. Accid Anal Prev 1998;30:379-387.

9. Man-Son-Hing M, Marshall SC, Molnar FJ, Wilson KG. Systematic review of driving risk and the efficacy of compensatory strategies in persons with dementia. J Am Geriatr Soc 2007;55:878-884.

10. Dawson JD, Anderson SW, Uc EY, Dastrup E, Rizzo M. Predictors of driving safety in early Alzheimer disease. Neurology 2009;72:521-527.

11. Crizzle AM, Classen S, Uc EY. Parkinson disease and driving: an evidence-based review. Neurology 2012;79:2067-2074.

12. Gorelick PB, Scuteri A, Black SE, Decarli C, Greenberg SM, Iadecola C, et al. Vascular contributions to cognitive impairment and dementia: a statement for healthcare professionals from the american heart association/american stroke association. Stroke 2011;42:2672-2713.

13. Debette S, Markus HS. The clinical importance of white matter hyper- 
intensities on brain magnetic resonance imaging: systematic review and meta-analysis. BMJ 2010;341:c3666.

14. Silbert LC, Nelson C, Howieson DB, Moore MM, Kaye JA. Impact of white matter hyperintensity volume progression on rate of cognitive and motor decline. Neurology 2008;71:108-113.

15. Pantoni L, Basile AM, Pracucci G, Asplund K, Bogousslavsky J, Chabriat $\mathrm{H}$, et al. Impact of age-related cerebral white matter changes on the transition to disability-the LADIS study: rationale, design and methodology. Neuroepidemiology 2005;24:51-62.

16. Scheltens P, Barkhof F, Leys D, Pruvo JP, Nauta JJ, Vermersch P, et al. A semiquantative rating scale for the assessment of signal hyperintensities on magnetic resonance imaging. J Neurol Sci 1993;114:7-12.

17. Son SJ, Lee KS, Lee Y, Baek JH, Choi SH, Na DL, et al. Association between white matter hyperintensity severity and cognitive impairment according to the presence of the apolipoprotein E (APOE) $\varepsilon 4$ allele in the elderly: retrospective analysis of data from the CREDOS study. J Clin Psychiatry 2012;73:1555-1562.

18. Kang Y ND, Hahn S. A validity study on the Korean mini-mental state examination (K-MMSE) in dementia patients. J Korean Neurol Assoc 1997:300-308.

19. Morris JC. The Clinical Dementia Rating (CDR): current version and scoring rules. Neurology 1993;43:2412-2414.

20. Mahoney FI, Barthel DW. Functional evaluation: the barthel index. Md State Med J 1965;14:61-65.

21. Ku HM KJ, Kwon EJ, Kim SH, Lee HS, Ko HJ, Jo S, Kim DK. A study on the reliability and validity of Seoul-Instrumental Activities of Daily Living (S-IADL). J Korean Neuropsychiatr Assoc 2004: 189-199.

22. Kang Y, Na DL. Seoul Neuropsychological Screening Battery (SNSB). Seoul: Human Brain Research \& Consulting Co; 2003.

23. Kim H, Na DL. Normative data on the Korean version of the Boston Naming Test. J Clin Exp Neuropsychol 1999;21:127-133.

24. Olsen K, Taylor JP, Thomas A. Mild cognitive impairment: safe to drive? Maturitas 2014;78:82-85.

25. Vaughan L, Hogan PE, Rapp SR, Dugan E, Marottoli RA, Snively BM, et al. Driving with Mild Cognitive Impairment or Dementia: Cognitive Test Performance and Proxy Report of Daily Life Function in Older Women. J Am Geriatr Soc 2015;63:1774-1782.

26. Mathias JL, Lucas LK. Cognitive predictors of unsafe driving in older drivers: a meta-analysis. Int Psychogeriatr 2009;21:637-653.

27. Adler G, Rottunda S, Dysken M. The older driver with dementia: an updated literature review. J Safety Res 2005;36:399-407.

28. Silva MT, Laks J, Engelhardt E. Neuropsychological tests and driving in dementia: a review of the recent literature. Rev Assoc Med Bras (1992) 2009;55:484-488.

29. Brown LB, Ott BR. Driving and dementia: a review of the literature. J Geriatr Psychiatry Neurol 2004;17:232-240.

30. Brown LB, Stern RA, Cahn-Weiner DA, Rogers B, Messer MA, Lannon MC, et al. Driving scenes test of the Neuropsychological Assessment Battery (NAB) and on-road driving performance in aging and very mild dementia. Arch Clin Neuropsychol 2005;20:209-215.

31. Ott BR, Anthony D, Papandonatos GD, D’Abreu A, Burock J, Curtin A, et al. Clinician assessment of the driving competence of patients with dementia. J Am Geriatr Soc 2005;53:829-833.

32. Szlyk JP, Myers L, Zhang Y, Wetzel L, Shapiro R. Development and assessment of a neuropsychological battery to aid in predicting driving performance. J Rehabil Res Dev 2002;39:483-496.

33. Reger MA, Welsh RK, Watson GS, Cholerton B, Baker LD, Craft S. The relationship between neuropsychological functioning and driving ability in dementia: a meta-analysis. Neuropsychology 2004;18:85-93.

34. Ott BR, Heindel WC, Papandonatos GD, Festa EK, Davis JD, Daiello LA, et al. A longitudinal study of drivers with Alzheimer disease. Neurology 2008;70:1171-1178.

35. Duchek JM, Carr DB, Hunt L, Roe CM, Xiong C, Shah K, et al. Longitudinal driving performance in early-stage dementia of the Alzheimer type. J Am Geriatr Soc 2003;51:1342-1347.
36. Iverson DJ, Gronseth GS, Reger MA, Classen S, Dubinsky RM, Rizzo M, et al. Practice parameter update: evaluation and management of driving risk in dementia: report of the Quality Standards Subcommittee of the American Academy of Neurology. Neurology 2010;74:1316-1324.

37. Uc EY, Rizzo M, Anderson SW, Sparks JD, Rodnitzky RL, Dawson JD. Driving with distraction in Parkinson disease. Neurology 2006;67:17741780.

38. Uc EY, Rizzo M, Johnson AM, Dastrup E, Anderson SW, Dawson JD. Road safety in drivers with Parkinson disease. Neurology 2009;73:21122119.

39. Alexander NB. Postural control in older adults. J Am Geriatr Soc 1994; 2:93-108.

40. Koo BB, Bergethon P, Qiu WQ, Scott T, Hussain M, Rosenberg I, et al. Clinical prediction of fall risk and white matter abnormalities: a diffusion tensor imaging study. Arch Neurol 2012;69:733-738.

41. Moscufo N, Guttmann CR, Meier D, Csapo I, Hildenbrand PG, Healy $\mathrm{BC}$, et al. Brain regional lesion burden and impaired mobility in the elderly. Neurobiol Aging 2011;32:646-654.

42. Srikanth V, Phan TG, Chen J, Beare R, Stapleton JM, Reutens DC. The location of white matter lesions and gait--a voxel-based study. Ann Neurol 2010;67:265-269.

43. Whitman GT, Tang Y, Lin A, Baloh RW. A prospective study of cerebral white matter abnormalities in older people with gait dysfunction. Neurology 2001;57:990-994.

44. Wolfson L, Wei X, Hall CB, Panzer V, Wakefield D, Benson RR, et al. Accrual of MRI white matter abnormalities in elderly with normal and impaired mobility. J Neurol Sci 2005;232:23-27.

45. Starr JM, Leaper SA, Murray AD, Lemmon HA, Staff RT, Deary IJ, et al. Brain white matter lesions detected by magnetic resonance [correction of resosnance] imaging are associated with balance and gait speed. J Neurol Neurosurg Psychiatry 2003;74:94-98.

46. Willey JZ, Scarmeas N, Provenzano FA, Luchsinger JA, Mayeux R, Brickman AM. White matter hyperintensity volume and impaired mobility among older adults. J Neurol 2013;260:884-890.

47. Inzitari D, Simoni M, Pracucci G, Poggesi A, Basile AM, Chabriat H, et al. Risk of rapid global functional decline in elderly patients with severe cerebral age-related white matter changes: the LADIS study. Arch Intern Med 2007;167:81-88.

48. Baezner H, Blahak C, Poggesi A, Pantoni L, Inzitari D, Chabriat H, et al. Association of gait and balance disorders with age-related white matter changes: the LADIS study. Neurology 2008;70:935-942.

49. Pohjasvaara TI, Jokinen H, Ylikoski R, Kalska H, Mantyla R, Kaste M, et al. White matter lesions are related to impaired instrumental activities of daily living poststroke. J Stroke Cerebrovasc Dis 2007;16:251-258.

50. Ylikoski R, Ylikoski A, Erkinjuntti T, Sulkava R, Raininko R, Tilvis R. White matter changes in healthy elderly persons correlate with attention and speed of mental processing. Arch Neurol 1993;50:818-824.

51. Moon SY, Na DL, Seo SW, Lee JY, Ku BD, Kim SY, et al. Impact of white matter changes on activities of daily living in mild to moderate dementia. Eur Neurol 2011;65:223-230.

52. Gouw AA, Van der Flier WM, van Straaten EC, Barkhof F, Ferro JM, Baezner H, et al. Simple versus complex assessment of white matter hyperintensities in relation to physical performance and cognition: the LADIS study. J Neurol 2006;253:1189-1196.

53. Pantoni L, Poggesi A, Basile AM, Pracucci G, Barkhof F, Chabriat H, et al. Leukoaraiosis predicts hidden global functioning impairment in nondisabled older people: the LADIS (Leukoaraiosis and Disability in the Elderly) Study. J Am Geriatr Soc 2006;54:1095-1101.

54. Ye BS, Seo SW, Kim GH, Noh Y, Cho H, Yoon CW, et al. Amyloid burden, cerebrovascular disease, brain atrophy, and cognition in cognitively impaired patients. Alzheimers Dement 2015;11:494-503. e493.

55. Fazekas F, Ropele S, Schmidt R. Can small-vessel disease-related cerebral abnormalities be used as a surrogate marker for vascular dementia trials? J Neural Transm Suppl 2002;(62):61-67. 